\title{
Update on Electronic Dental Record and Clinical Computing Adoption Among Dental Practices in the United States
}

\author{
Amit Acharya, BDS, PhD; Dixie Schroeder, MBA; Kelsey Schwei, PhD; and Po-Huang Chyou, PhD
}

\begin{abstract}
This study sought to re-characterize trends and factors affecting electronic dental record (EDR) and technologies adoption by dental practices and the impact of the Health Information Technology for Economic and Clinical Health (HITECH) act on adoption rates through 2012. A 39-question survey was disseminated nationally over 3 months using a novel, statistically-modeled approach informed by early response rates to achieve a predetermined sample. EDR adoption rate for clinical support was $52 \%$. Adoption rates were higher among: (I) younger dentists; (2) dentists $\leq 15$ years in practice; (3) females; and (4) group practices. Top barriers to adoption were EDR cost/expense, cost-benefit ratio, electronic format conversion, and poor EDR usability. Awareness of the Federal HITECH incentive program was low. The rate of chairside computer implementation was $72 \%$.Adoption of EDR in dental offices in the United States was higher in 2012 than electronic health record adoption rates in medical offices and was not driven by the HITECH program. Patient portal adoption among dental practices in the United States remained low.
\end{abstract}

Keywords: Dental Informatics; Dental Records; Dentistry; Electronic Health Records; Meaningful Use

$\mathrm{U}$ se of computers in dental offices in the United States has become more commonplace over the last three decades. In 1984, $11 \%$ of general dental practices used computers in their offices, ${ }^{1}$ with rates increasing to $>85 \%$ of 166,000 dental practices in the United States by 2009. ${ }^{2}$ While further adoption of electronic dental records (EDRs) by dental practices has been low, substantial growth in adoption specifically of clinical computing and EDRs by U.S. dental practitioners has occurred, especially within the last decade. In a comprehensive investigation through 2006 on adoption, utilization rates, and attitudes toward clinical computing among general U.S. dental practitioners, Schleyer et $\mathrm{al}^{1}$ reported that $25 \%$ of dental practitioners used a chairside computer, and $1.8 \%$ of dental practitioners were completely paperless. A survey of dentists conducted by the American Dental Association (ADA) from 2006 to 2007 reported further expansion of rates to $55.5 \%$ with chairside computers and $9.2 \%$ paperless practices. $^{3}$ A 2010 survey of California dentists ${ }^{4}$ showed that $23 \%$ had fully implemented an EDR in their practice. A recent survey of the Dental Practice-based
Research Network reported EDR implementation by $14.3 \%$ of solo practitioners and $15.9 \%$ of group practitioners. ${ }^{5}$

The Health Information Technology for Economic and Clinical Health (HITECH) Act authorized \$30 billion in incentives to increase the adoption of certified electronic health records (EHRs) for meaningful use.,7 Incentive payments range from a $\$ 44,000$ maximum under the Medicare incentive option to $\$ 64,000$ under the Medicaid program for each eligible provider. ${ }^{6}$ Although dentists are eligible professionals under the HITECH incentive program, the impact of this program on EDR adoption by dental practices has not been evaluated to date. A proportion of U.S. dentists may not qualify for this incentive program, since they do not meet the minimum requirement of serving a patient population inclusive of a $30 \%$ rate of Medicaid beneficiaries. Further, a formal definition of "meaningful use" for dentistry within the context of the regulatory definition is lacking.
Corresponding Author: Amit Acharya, BDS, PhD, Director, Marshfield Clinic Research Institute, 1000 North Oak Avenue, Marshfield,WI 54449 USA

Email:Acharya.amit@marshfieldresearch.org

\author{
Received: August 10, 2017 \\ Revised: November 8, 2017 \\ Accepted: November 21, 2017 \\ doi: $10.3121 / \mathrm{cmr} .2017 .1380$
}

Financial Support: This study was supported in part by funds from Marshfield Clinic Research Institute, Family Health Center of Marshfield, Inc., and Delta Dental of Wisconsin. 
Following-up on this historical perspective, this study's main objective was to gain greater insight into perceptions surrounding current EDR implementation in the dental practice setting and reassess the extent of adoption of EDR systems among a random selection of dental practices in the United States. Two further objectives included: (1) assessing knowledgeability concerning the recent HITECH EHR incentive program and meaningful use among dental practitioners, and (2) obtaining insight into other technologyrelated practice applications by investigating attitudes towards, and utilization of, clinical computing in dentistry.

\section{Methods}

Review of previously-published survey tools revealed that no existing tool satisfactorily encompassed the total focus of the current study. Thus, expansion of a survey tool created by Schleyer et al $^{1}$ was undertaken, incorporating multi-level questions germane to analyzing study objectives. The 39 questions were grouped into 7 broad categories (Table 1). Face and content validity analysis of the survey was conducted by coauthors with appropriate expertise before use. The research protocol and survey instrument met exemption criteria from ongoing oversight following Institutional Review Board review. The survey tool (Appendix 1) was beta tested by dentists and staff from dental centers operationalized by the Family Health Center of a multi-specialty clinic, in Wisconsin, USA, before dissemination.

A random list of 8,000 dentists actively practicing in the United States and their contact information was purchased from Hippo Direct, an authorized licensee of the ADA. A novel approach to survey dissemination was piloted ${ }^{10}$. Briefly, the survey was mailed in phases. Return rates on the first two sub-samples, which randomly targeted the available mailing list, were modeled to determine the number of mailings required in the final distribution of surveys to attain a targeted sample size $(n=400)$. Phasic survey distributions were undertaken over a 3-month window between August and October of 2012. To enhance the probability of response, within a 3-week window respondents were given the option of completing a mailed, paper-based survey; an online survey; or a telephone interview.

All surveys collected during the 3-month window in 2012 were included in the analysis. Data collected in the surveys were entered into the SurveyMonkey tool/database, exported into Excel (Microsoft Corporation, Seattle, WA), and converted to SAS Windows version 9.2, English (SAS Institute Inc., Cary, NC). A data entry/quality assurance clerk manually validated data entry on $10 \%$ of surveys to verify accuracy.

\section{Statistical Analysis}

For the defined categorical variables, frequency distributions (percentages) were compared, and corresponding $P$ values were derived by Chi-square testing. For specific continuous variables, median values were compared, and corresponding $P$ values were derived using Wilcoxon Rank Sum test. All data analyses were carried out using SAS Windows version 9.2, English.

Content analysis of free-text of open-ended responses from participants was performed to systematically and objectively draw valid inferences from verbal, visual, or written data. An

Table 1. Classification of the 39 multi-level questions across seven broad categories.

\section{Categories by Subject}

Provider demographics

Practice demographic

Technology at practice

EDR adoption

Meaningful Use/American Recovery and Reinvestment Act (ARRA)

Nationwide Health Information Network (NHIN)/Health Information Exchange (HIE)

Method of storage \& date entry responsibility/ modalities (EDR)

EDR, electronic dental record

\section{Category Description}

Provider's age, gender, ethnicity, graduating dental school; years in practice

Type of practice (solo or group practice), areas of specialty; number of staff, geographic location of practice - state, rural, suburban, urban, number of operatories

Use/location of computers, devices/technologies used, Internet use, patient portal, patient education, use of social media

Adoption rates, practice management systems, input mechanisms, comfort level of staff, input regarding advantages and disadvantages of EDR, attitudes and perceptions of EDRs Level of familiarity/interest in Meaningful Use \& ARRA, advantages and disadvantages of ARRA, intentions to apply for ARRA incentive program, implementation barriers or challenges

NHIN level of familiarity, participation, and interest; and other HIE level of familiarity, interest and participation, number of practices in network, type of information shared

Type of information, storage methods - paper, computer or both, data entry responsibilities 


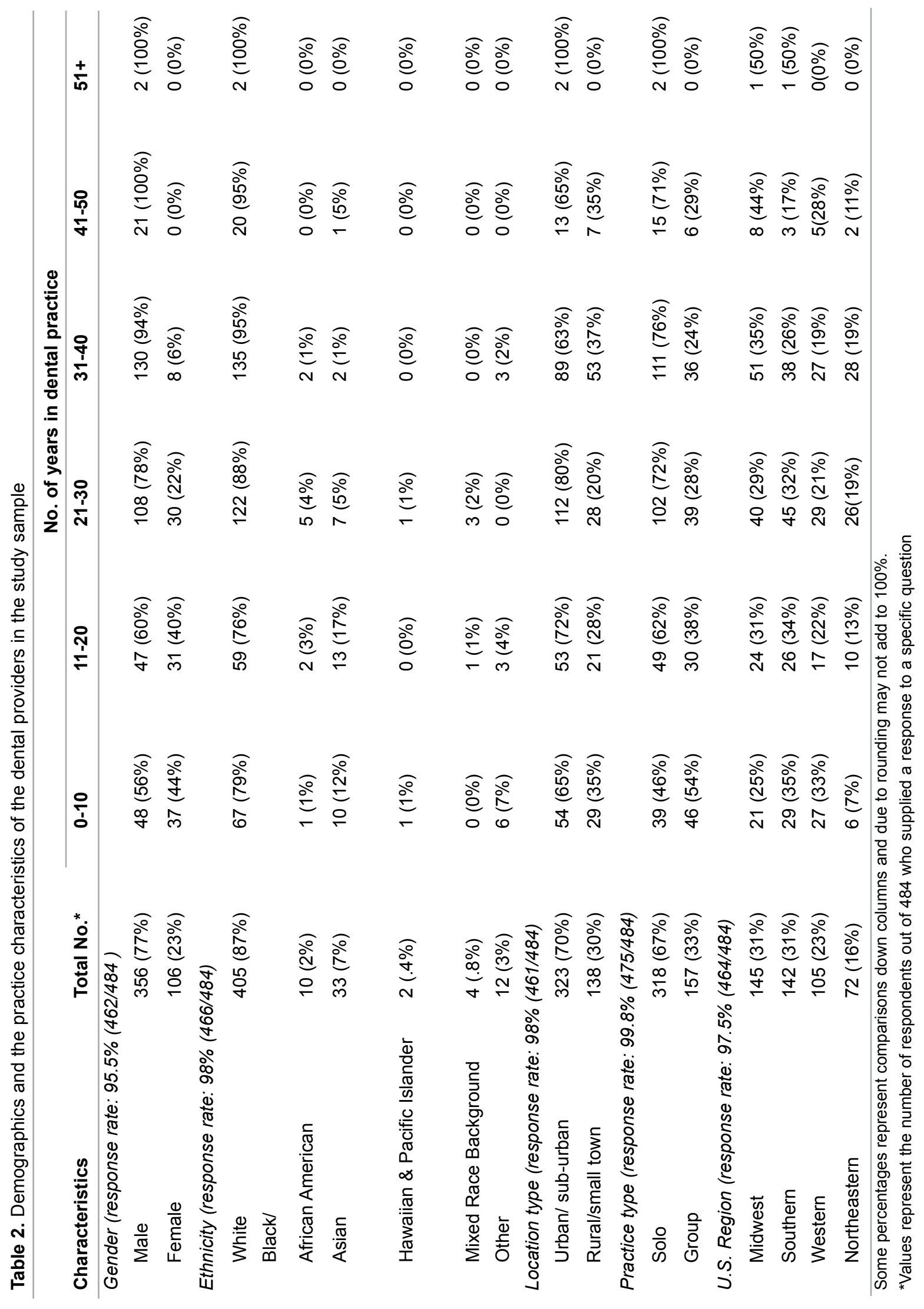


inductive approach was applied to raw data ${ }^{11}$ to identify and capture detailed factors and categories emerging from openended questions. ${ }^{12}$ Responses to all open-ended questions were iteratively reviewed while developing thematic coding frames for each question. Emergent themes based on content analyses conducted by co-authors with expertise in qualitative analysis were regrouped into larger categories.

\section{Results}

Survey Administration

Staged dissemination of surveys achieved a return rate that exceeded the targeted $n=400$ by $21 \%$, capturing an actual return rate of 484 surveys. Of the 484 respondents returning the survey, $434(89.7 \%)$ completed the mailed, paper-based survey, while the remaining 50 respondents $(10.3 \%)$ elected to complete the survey online through SurveyMonkey. No respondents engaged telephonic survey completion. Not all 484 respondents answered all the 39 questions

\section{Demographics and Practice Characteristics}

Table 2 illustrates the demographics and practice characteristics of survey respondents and highlights observed differences among respondents' characteristics. Participants were generally older (age $>50$ years) with $62 \%(301 / 482)$ reporting their age as over 50 years. Of the respondents, $65 \%$ (299/462) reported being in practice for more than 20 years. Only approximately one-quarter of respondents was female. Twothirds of respondents (324/483) were in solo practice settings. Over half (53/94) of younger respondents (age $\leq 40$ years) worked in a group practice, while $73 \%(282 / 387)$ of respondents over age 40 worked in a solo practice. Nearly half (217/474) of respondents practiced in suburban settings, followed by $31 \%(146 / 474)$ in rural/small town areas, and $24 \%(116 / 474)$ in urban areas. US regional representation of the respondents included: Midwest 31\% (145/472); South $30 \%(142 / 472)$; West 22\% (105/472); and Northeast $15 \%$ (72/472).
Table 3 summarizes comparison of study respondents gender, solo/group practice split, and demographic location within the United States, compared to a national sample of dentists from the 2012 ADA National Sample of Dentists Survey. ${ }^{12,13}$ The current study captured a significantly higher response from Midwestern states compared to ADA response rates from the same region $(\mathrm{P}<0.0001){ }^{13,14}$ However, no statistically significant difference was observed in response rates regionally across the nation in the current study, although comparatively higher response rates were achieved among Midwestern and Southern practices compared to those achieved among Northeastern states. Approximately twothirds of respondents in the current study reported being in solo practice settings.

\section{Technology at Practice}

Use of computers chairside in operatories was reported by $72 \%(341 / 476)$ of practices, with $46 \%$ (158/341) reporting chairside internet connectivity. A majority of respondents reported having computers at the front office desk (458/476) or in provider or staff offices (382/476), and 11\% (54/476) reported providing computer access in patient waiting areas. Moderate-to-high comfort levels with computers were reported by $83 \%$ (396/477) of respondents, while $9 \%$ (41/477) indicated low to very-low comfort levels.

The majority of respondents assigned relatively high importance to internet access in their practices, with $79 \%$ (378/476) rating it as 'somewhat to very essential.' Practicerelated internet searches were reported to access the following: vendor/products (358/474), educational material (358/474), evidence-based information (228/474), referrals (179/474), technology support (175/474), and 'other purpose' (54/474). Technologies/devices used in their practice included: iPads/ tablets (83/146), Smart Phones/personal digital assistants (104/146), digital radiographs (263/484), and computer-aided design-computer-aided manufacturing (CAD-CAM) (73/484).

Table 3. Study respondents in solo or group practice compared to data reported in the 2012 ADA National Sample of Dentists Survey* $(n=188,820){ }^{12,13}$

\begin{tabular}{llll}
\hline & Our study & ADA & $\boldsymbol{P}$ value \\
\hline Gender & & & 0.1248 \\
Male & $77 \%$ & $74 \%$ & \\
Female & $23 \%$ & $26 \%$ & $<0.0001$ \\
Practice Type & & & \\
Solo & $67 \%$ & $57.5 \%$ & $<0.0001$ \\
Group & $33 \%$ & $42.5 \%$ & \\
Geographical location & & & \\
Midwest & $31 \%$ & $20 \%$ & \\
Southern & $31 \%$ & $32 \%$ & \\
Western & $23 \%$ & $27 \%$ & \\
Northeastern & $16 \%$ & $21 \%$ & \\
\hline
\end{tabular}

*The denominator for each row of this table is $n=475$ respondents. 
Table 4. Dental personnel responsible for entering data in various information categories

\begin{tabular}{|c|c|c|c|c|}
\hline Information Type & Dentist & Hygienist & Assistant & Front Desk \\
\hline Patient Accounting \& Billing & $84(18 \%)$ & $78(16 \%)$ & $88(19 \%)$ & $422(89 \%)$ \\
\hline Insurance Details & $43(9 \%)$ & $30(6 \%)$ & $55(12 \%)$ & $419(88 \%)$ \\
\hline Expense Reports & $169(36 \%)$ & $11(2 \%)$ & $28(6 \%)$ & $252(53 \%)$ \\
\hline Patient Appointments & $96(20 \%)$ & $183(39 \%)$ & $199(42 \%)$ & $409(86 \%)$ \\
\hline Chief complaint & $274(58 \%)$ & $192(40 \%)$ & $201(42 \%)$ & $146(31 \%)$ \\
\hline Oral health status & $328(69 \%)$ & $269(57 \%)$ & $199(42 \%)$ & $84(18 \%)$ \\
\hline Alerts & $244(51 \%)$ & $232(49 \%)$ & $245(52 \%)$ & $307(65 \%)$ \\
\hline Prescriptions & $361(76 \%)$ & $122(26 \%)$ & $141(30 \%)$ & $152(32 \%)$ \\
\hline Medication history & $288(61 \%)$ & $263(55 \%)$ & $244(51 \%)$ & $218(46 \%)$ \\
\hline Dental history & $318(67 \%)$ & $268(56 \%)$ & $255(54 \%)$ & $138(29 \%)$ \\
\hline Medical history & $289(61 \%)$ & $257(54 \%)$ & $239(50 \%)$ & $202(43 \%)$ \\
\hline Social history & $191(40 \%)$ & $172(36 \%)$ & $173(36 \%)$ & $163(34 \%)$ \\
\hline Family dental history & $199(42 \%)$ & $173(36 \%)$ & $168(35 \%)$ & $133(28 \%)$ \\
\hline Family medical history & $210(44 \%)$ & $177(37 \%)$ & $167(35 \%)$ & $129(27 \%)$ \\
\hline Intra-oral examination & $353(74 \%)$ & $257(54 \%)$ & $201(42 \%)$ & $42(9 \%)$ \\
\hline Extra-oral examination & $348(73 \%)$ & $237(50 \%)$ & $183(39 \%)$ & $35(7 \%)$ \\
\hline Periodontal charting & $256(54 \%)$ & $319(67 \%)$ & $188(40 \%)$ & $36(8 \%)$ \\
\hline Tooth charting & $293(62 \%)$ & $292(61 \%)$ & $284(60 \%)$ & $36(8 \%)$ \\
\hline Test results & $271(57 \%)$ & $133(28 \%)$ & $147(31 \%)$ & $119(25 \%)$ \\
\hline Intra-oral images & $259(55 \%)$ & $259(55 \%)$ & $287(60 \%)$ & $45(9 \%)$ \\
\hline Extra-oral images & $241(51 \%)$ & $195(41 \%)$ & $239(50 \%)$ & $51(11 \%)$ \\
\hline Radiographic images & $259(55 \%)$ & $311(65 \%)$ & $336(71 \%)$ & $53(11 \%)$ \\
\hline $\begin{array}{l}\text { Consults/reports to/from other } \\
\text { dentists or health providers }\end{array}$ & $293(62 \%)$ & $107(23 \%)$ & $127(27 \%)$ & $248(52 \%)$ \\
\hline Risk assessment & $276(58 \%)$ & $148(31 \%)$ & $92(19 \%)$ & $40(8 \%)$ \\
\hline Problem list & $287(60 \%)$ & $178(37 \%)$ & $164(35 \%)$ & $82(17 \%)$ \\
\hline Treatment plans & $351(74 \%)$ & $192(40 \%)$ & $196(41 \%)$ & $171(36 \%)$ \\
\hline Diagnoses & $379(80 \%)$ & $143(30 \%)$ & $118(25 \%)$ & $40(8 \%)$ \\
\hline Prognosis & $369(78 \%)$ & $132(28 \%)$ & $108(23 \%)$ & $30(6 \%)$ \\
\hline Progress notes & $372(78 \%)$ & $270(57 \%)$ & $204(43 \%)$ & $58(12 \%)$ \\
\hline Completed treatment & $334(70 \%)$ & $227(48 \%)$ & $213(45 \%)$ & $146(31 \%)$ \\
\hline Patient education / instructions & $321(68 \%)$ & $288(61 \%)$ & $278(59 \%)$ & $130(27 \%)$ \\
\hline
\end{tabular}

Methods of Information Storage

Table 4 summarizes dental personnel involved in the data entry of various types of information at the dental centers. As indicated by significant $P$ values, activities tend to compartmentalized based on roles. Front desk personnel primarily entered data associated with patient accounting, insurance details, expense reports, and patient appointments. Dental assistants primarily entered intra-oral images and radiographic images. Dental hygienists primarily captured data associated with periodontal charting, and dentists primarily entered oral health status, prescriptions, intra- and extra-oral examinations, test results, consults/reports to/from other dentists or health providers, risk assessment, problem list, treatment plans, diagnosis, prognosis, progress notes, and completed treatment.

More than two-thirds of respondents stored administrative information such as expense reports, insurance details, patient 


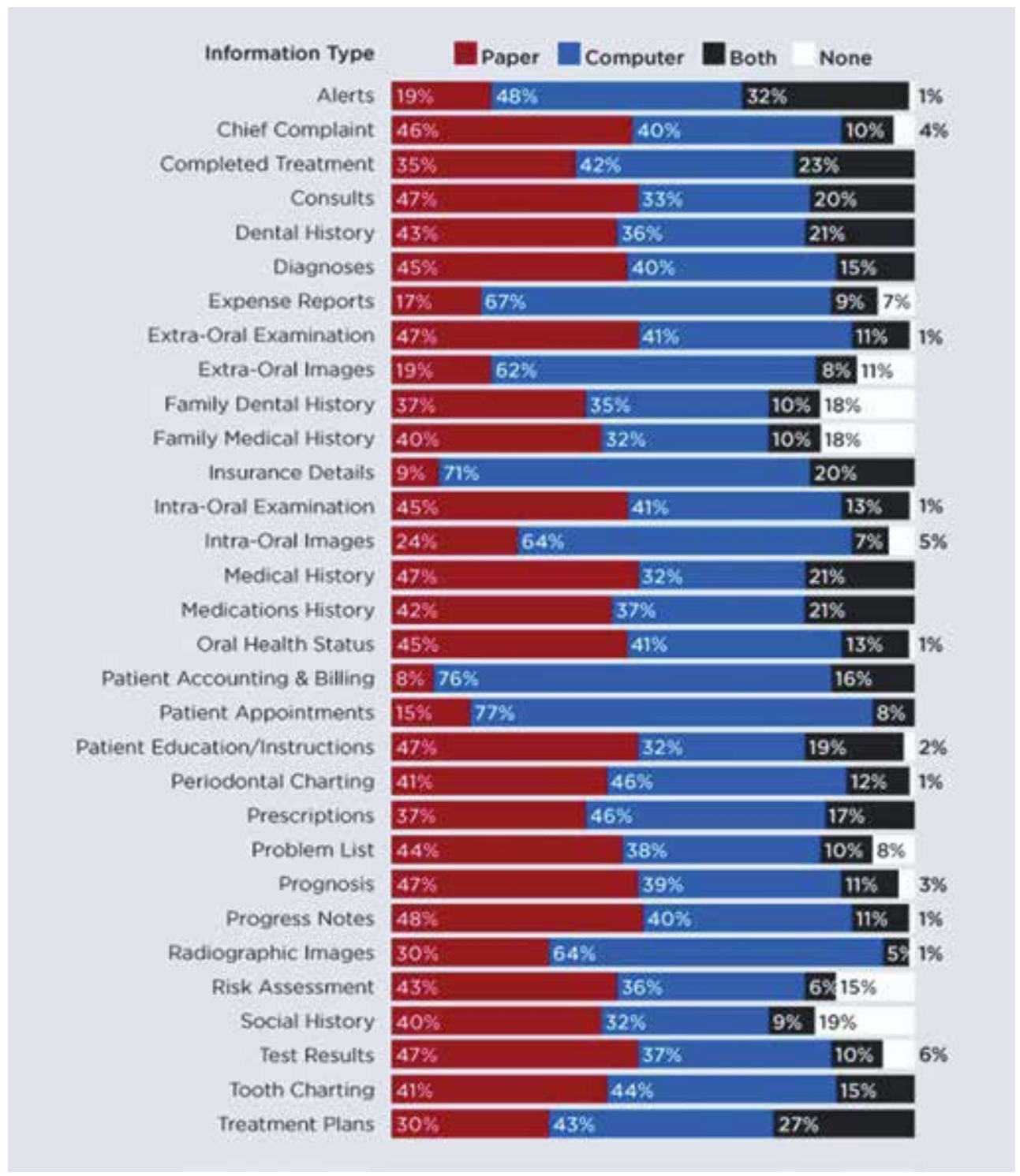

Figure 1. Information storage methods of major clinical and administrative information in dental practices.

appointment, patient accounting, and billing entirely on computers. A proportionately large number of respondents stored clinical images completely on computers: intra-oral images 64\% (295/458), extra-oral images 62\% (280/448), and radiographic images $64 \%(295 / 463)$. Our results showed that dental providers stored administrative information such as insurance details, patient appointment, patient accounting, and billing and treatment plan either on paper, computer, or both, with the exception of expense reports, which were not stored at all among $6 \%$ of the respondents. With respect to clinical information, $\leq 5 \%$ of respondents neither stored information on paper nor on a computer for the following types of information: alerts, chief complaint, intra-oral and extra-oral examination, intra-oral images, oral health status, patient education/instructions, periodontal charting, prognosis, progress notes, and radiographic images. Between 6\%-19\% of respondents reported that clinical information including extra-oral images, family medical history, family dental history, problem list, risk assessment, social history, and test results were neither stored on paper nor on computer. Figure 1 captures the different mediums used by the dental providers across the United States to store major clinical and administrative information in their practices.

\section{Patient-centric Practice}

Formats used most frequently for patient education by respondents included: face-to-face 93\% (447/480); take-away paper-brochures/walk-out statements $89 \% \quad(427 / 480)$; electronic_computer/video/CDs 42\% (203/480); and Internet $31 \%(150 / 480)$. When asked what resources were used for patient education, 79\% (373/471) cited their own clinical materials; 30\% (141/471) listed software applications; and $14 \%(64 / 471)$ listed other resources.

Among the 15\% (70/476) of respondents who had patient portals at their practice, the following features/capacities were available: patient forms and online services $68 \%(46 / 68)$; viewing and/or scheduling appointments 53\% (36/68); 


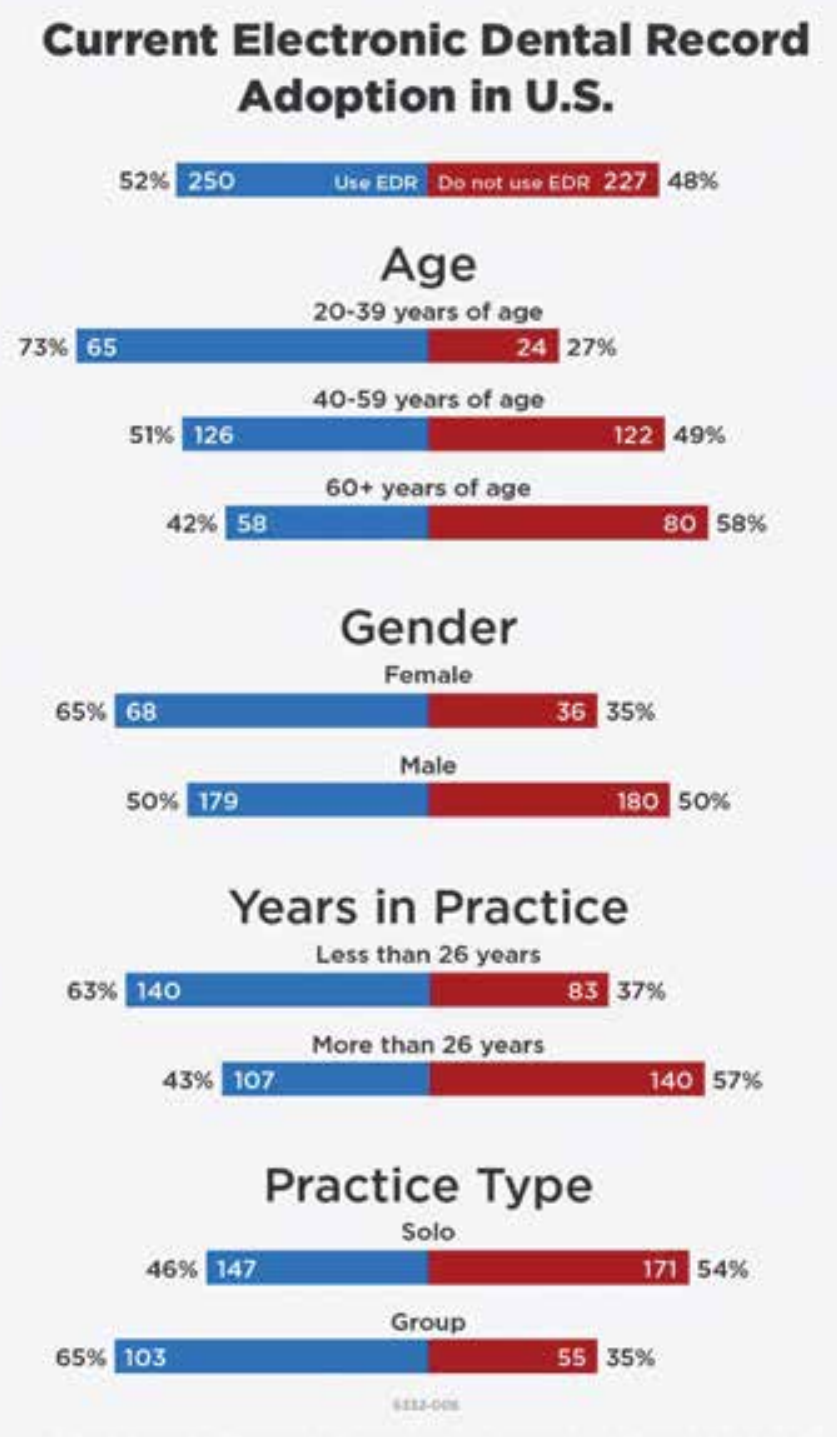

Figure 2. Demographics and practice characteristics of dentists who are using electronic dental records (EDRs) versus the dentists not engaging EDRs.

updating insurance information 53\% (36/68); bill payment $41 \%(28 / 68)$; health reminders 40\% (27/68); educational health information $40 \%(27 / 68)$; health summary $21 \%(14 / 68)$; refilling prescriptions $9 \%(6 / 68)$; and reviewing test results $1 \%(1 / 68)$.

Among respondents, 38\% (184/480) used social media including the following venues: Facebook, 95\% (175/184); Twitter, 26\% (48/184); LinkedIn, 23\% (42/184); and YouTube, $15 \%(28 / 184)$. Dental practices indicated using social media for marketing $(87 \%, 154 / 177)$, communication $(71 \%$, $125 / 177)$, and networking $(60 \%, 106 / 177)$.

\section{Electronic Dental Record Adoption and Usage}

Figure 2 illustrates demographics and practice characteristics of responding practices reporting EDR use versus no EDR use. Among respondents with EDRs, 73\% (347/475) indicated EDRs were 'moderately to very important' for their practice.
Comfort level with use of EDRs was ranked as, 'very or somewhat comfortable' by 53\% (248/472), while $23 \%$ (109/472) selected 'somewhat or very uncomfortable'. Figure 3 depicts word clouds that summarize emergent themes representing perceived advantages (Figure 3a) and disadvantages (Figure 3b) of EDRs as described by the respondents.

Current EDR use was reported by $52 \%$ (250/477) of respondents with $40 \%$ of practices $(101 / 250)$ reporting "going live" with their EDR more than 6 years ago, 29\% (73/250) 3-5 years ago, while $28 \%(70 / 250)$ reported startup within the last 2 years. The remaining 48\% (227/477) of respondents that indicated they were not currently using EDRs in their practice were asked to provide a rationale for lack of adoption. The top four reasons indicated for not using EDRs were: cost/expense $28 \%(33 / 116)$; low value placed on EDR implementation $16 \%$ (19/116); time investment to convert/train staff $16 \%(18 / 116)$; 
and poor usability/comfort level with computers $8 \%(9 / 116)$. Of the current non-adopters, 40\% (91/227) were unsure of whether they would adopt an EDR in the future, and 33\% (74/277) indicated no interest in adopting an EDR. Among the respondents planning potential future EDR adoption, 4\% $(10 / 227)$ were planning adoption in the next 6 months, $4 \%$ $(8 / 227)$ in the next $7-11$ months, $10 \%(23 / 227)$ in the next $1-2$ years, and $4 \%(8 / 227)$ in $>2$ years.

\section{Provider's Perception of EDRs}

With respect to perceptions on the relative security offered by paper versus EDRs, 36\% (173/276) of respondents felt the paper version offered more security, while an additional $36 \%$ $(173 / 276)$ of respondents electronic dental records provided a higher level of security. Among respondents, 64\% (308/478) agreed that EDRs improve efficiency among dental staff. When asked about cost benefit, 25\% (117/468) agreed that EDR cost exceeds the relative value to the practice, while 41\% (191/468) disagreed. Regarding data entry, 37\% (176/474) of respondents disagreed that more time is required to enter data into EDRs than to a paper record, while $33 \%$ (159/477) agreed. When asked whether EDRs improve patient care, 44\% (212/478) of the respondents agreed. When asked whether they would recommend EDRs to dentists starting a new practice, $75 \%(359 / 477)$ of respondents noted they would, and $85 \%(402 / 474)$ agreed that EDRs improve legibility. Figure 4 illustrates dental providers' perceptions of EDRs.

\section{Electronic Health Record Incentive Program}

Among respondents, 75\% (357/474) were unfamiliar with the National Health Information Network (NHIN)/Health Information Exchange (HIE). Further, 73\% (348/478) of respondents lacked familiarity with the Meaningful Use/ American Reinvestment and Recovery Act (MU/ARRA) incentives available for implementation of EHRs. When asked if they planned to apply for the MU/ARRA incentive program, $59 \%(273 / 459)$ were unsure, and 25\% (117/459) did not plan to apply. For those respondents already participating in MU/ ARRA $(n=22), 45 \%(10 / 22)$ reported no barriers or challenges to certification for $\mathrm{MU}$, while $27 \%$ (6/22) reported not meeting the minimum qualification for patient coverage. Among practitioners who identified barriers to EDR adoption, $18 \%(4 / 22)$ named inability to identify a certified EDR system

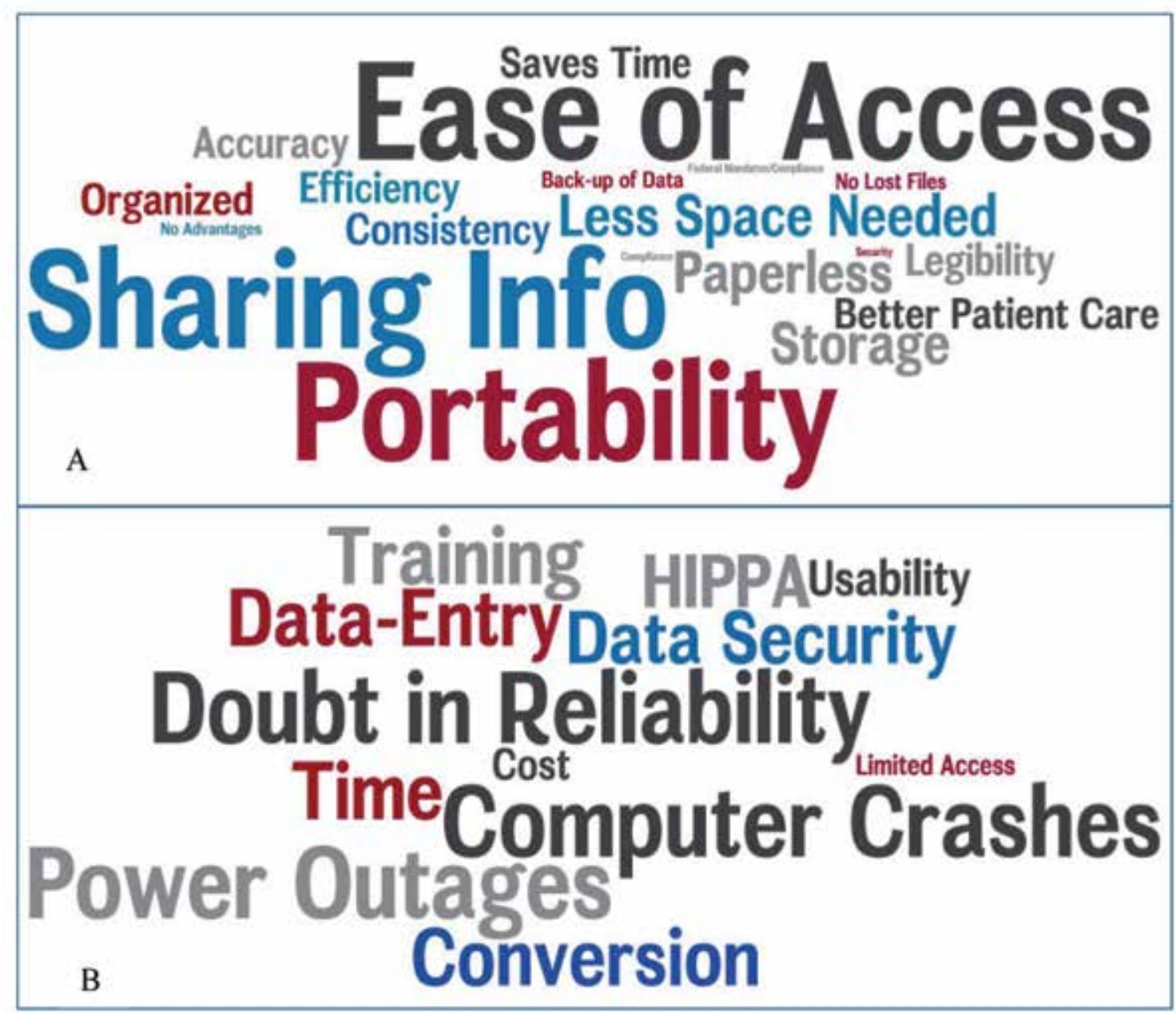

Figure 3. (A) Word cloud summarizing key themes described by the respondents that represent the advantages of electronic dental records (EDRs). (B) Word cloud reflecting key themes advanced by respondents surrounding disadvantages of EDRs. Thematic emphasis is shown proportionately by the size of the words depicting the theme reflecting frequency of expression of the theme by participants. 


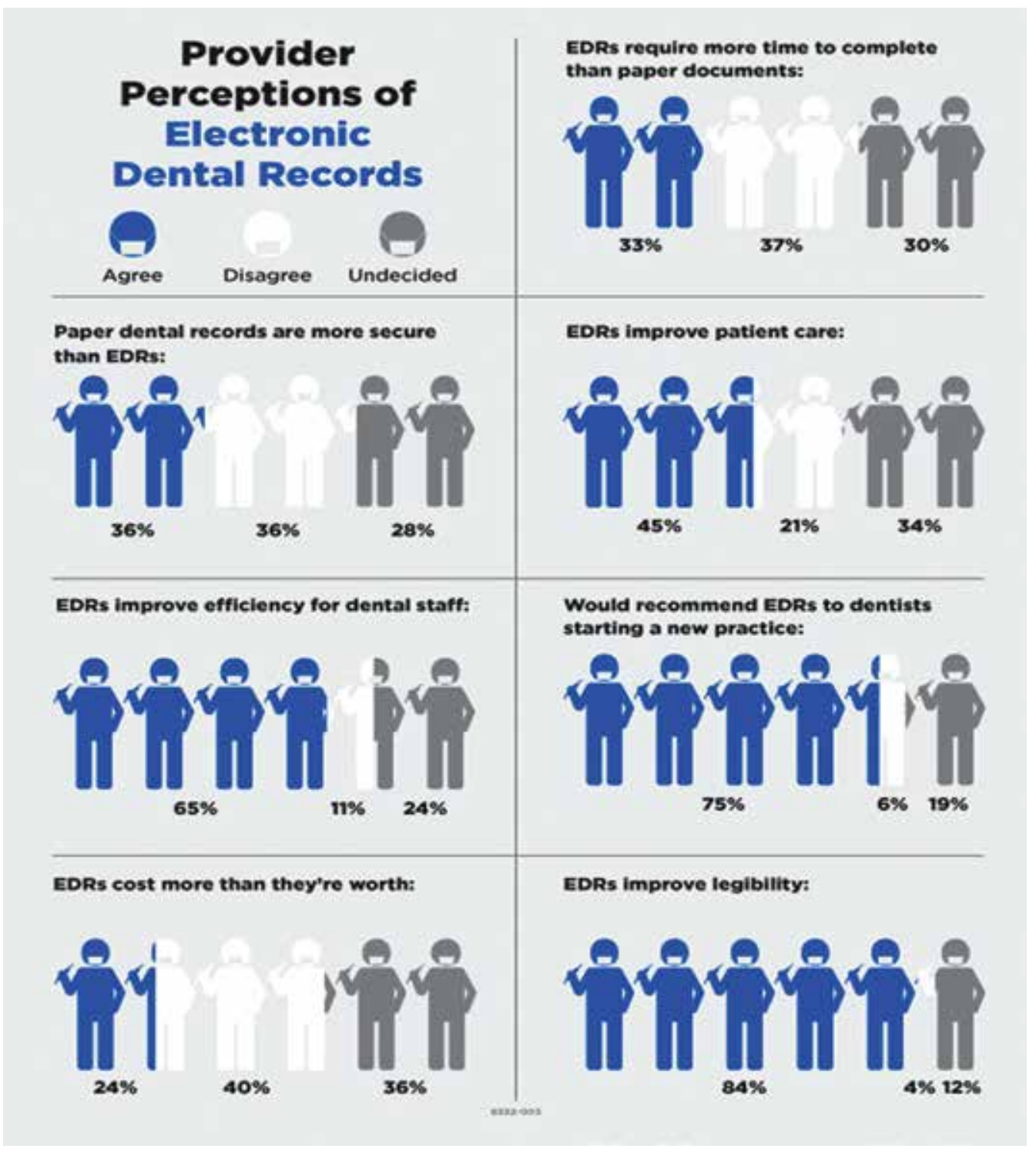

Figure 4. Dental providers' perception of electronic dental records (EDRs) summarized in this figure depicts extent of agreement (or disagreement) with statements presented to them about EDRs.

to suit their practice as a core barrier, while $0.5 \%(1 / 22)$ noted difficulty in meeting the defined MU core/menu objectives and clinical quality measures as barriers.

\section{Discussion}

The results of this study contributed to better understanding of the current knowledge, trends, extent of adoption of EDR systems, perceptions, and attitudes regarding the utilization of clinical computing among U.S. dental practices. Our study represents the most current national survey study relative to EDR adoption among dental practices in the United States conducted at the national level since the HITECH Act adoption in 2009.

Among the sample of nationwide respondents, high rates of computer utilization to support office and practice management in dental practices were captured, especially in the context of patient appointing and billing. Further, introduction of computer access in patient waiting areas is slowly emerging in dental practices, with potential to support patient check-in, providing an alternative venue for patients to access educational materials, as well as the availability of a patient portal to support updates to medical, medication, and dental history in the future. Our study results reported a $72 \%$ rate of chairside computer use, increasing the rates of $25 \%$ and $55 \%$ reported in 2005 and 2006-2007, respectively. An increased trend in internet access via chair-side computers among dental providers was noted, with practitioners electronically accessing products/vendor information, patient educational materials, and evidence-based data for clinical decision support.

Our results supported findings from a previous study ${ }^{1}$ that reported administrative information storage was predominantly captured by computers in dental practices. Our study noted an increase of $\geq 20 \%$ in computer use for storing chief complaint, 
dental history, medical history, and radiographic images by U.S. dental providers since the previous study conducted by Schleyer et al in 2006. ${ }^{1}$ However, several important differences should be noted between the methodological approaches of the two studies.

Whereas the study by Schleyer et $\mathrm{al}^{1}$ used a telephonic interview approach and required interviewees to have a computer to achieve study eligibility, the current study used a survey approach and had no similar exclusion criteria. Further, Schleyer's study screened 1039 practices to identify 256 practices that indicated potential willingness to engage the study and completed 102 interviews among eligible receptive practices. ${ }^{1}$ Our study engaged a novel approach, which screened historical dental survey literature for definitions of sample sizes and response rates achieved in previous dental survey studies, to identify a robust sample size and then statistically modeled the estimated response rate required to achieve the target. ${ }^{10}$ Response rate projection was informed by true response rates achieved by two initial mailings and then estimating total numbers of mailing required to achieve the targeted sample. This approach was highly successful in achieving the targeted response, requiring only two-thirds of potential recipients to be targeted, while still exceeding the targeted goal by $20 \%$.

To examine whether the approach targeted a representative population, we compared our demographic data with that captured by a large national ADA survey relative to respondents' gender, solo/group practice split, and demographic location within the United States to see if statistically significant differences were observable. As shown in Table 3, statistical differences were noted between our respondents and those of the ADA survey for geographic location and practice type (solo vs group practice). Our study achieved a significantly higher response rate from Midwestern institutions compared to those achieved for the national ADA survey (Figure 4). Higher response to our survey may be attributable to our Midwestern geographic location and its regional visibility to Midwest practices. Notably, among the surveys returned, a range of EDR adoption rates across practices was noted, increasing the likelihood that the sample was representative. However, the reproducibility of this approach remains to be further validated in future studies.

Due to reports that response rates to surveys among dental practices are declining, ${ }^{15}$ an alternative strategy was developed for modeling survey return rates to achieve a projected sample size proved to be a novel, cost-effective approach to achieving a representative response free of bias to achieve valid survey outcomes ${ }^{10}$. When compared to the alternative approach involving enrollment of special populations to increase the probability of a high response rate, ${ }^{5}$ which is potentially prone to bias because the targeted population may not represent the national experience and may therefore not be generalizable, this approach supported random sampling nationally and yielded representative outcomes despite targeting a more modest sample size.

More than $20 \%$ of respondents indicated storage of alerts, completed treatment, dental history, medical history, medication history, and treatment plan on both paper and computers, indicating continued existence of hybrid data storage among some dental practices. The family medical/ dental history provides an opportunity to connect with the patient as an individual and can be used to monitor for the presence of disease, guide physical examination, and inform strategies for clinical testing to support provision of cost effective, evidence-based care. ${ }^{16}$ Although family medical history, family dental history, and social history were stored in electronic and/or paper format by the majority of the respondents in their practice, nearly $18 \%$ of respondents reported not storing the information in these formats.

Notably, our findings were in good agreement with a study published by Schleyer et $a l^{5}$ who conducted a study similar in approximately the same time frame among the Dental Practice-Based Research Network (DPBRN), a subset of dental practitioners with membership in a research network, surrounding EDR and computer use in the dental clinical setting. The authors reported a robust response rate of $74 \%$ among the 991 DPBRN participants of their web-based survey approach and reported rates of computer use for management of clinical information at $74 \%$ and $78.7 \%$ among solo and group practitioners, respectively. Similarly, our study reported an average rate of chairside computer use of $72 \%$ across all practice types in our national survey of dental clinicians. Notably, our ratio of solo practice to group practice participants was approximately $2: 1$. Close agreement in the findings reported by both studies further validated capacity of our targeted sample size approach to accurately quantify adoption of technology in the clinical setting.

A main focus of this study, which has not been examined to date, was to explore whether rising EHR adoption rates among physicians and hospitals in the United States may be partially attributable to incentivisation by the HITECH Act passed in February 2009. ${ }^{17}$ Although our study data indicated that U.S. dentists were generally unfamiliar with the EHR incentive program ${ }^{18,19}$ available to them, it nevertheless documented a higher adoption rate of EDRs by U.S. dentists in the same time frame compared to medical practices rates reported in the study by Hsaio et $\mathrm{al}^{20}{ }^{20}$ which was based on data surrounding rates of basic EHR system adoption reported by the Office of National Coordinator reported in $2012^{21}$ (data summarized in Table 5). The U.S. dentists surveyed in our study in 2012 reported a 52\% EDR adoption rate, with the dentists in the Midwest showing highest adoption rates. Highest EHR adoption rates in 2012 were also reported among Midwestern practitioners. By comparison, a 2016 systematic review ${ }^{22}$ that explored trends in EHR adoption cited a study reporting only $55 \%$ of providers nationwide 
were in compliance with the HITECH act at the end of 2014. ${ }^{23}$ The systematic review further identified 25 facilitating factors and 23 barriers to EHR adoption. ${ }^{22}$ Cost of EHR adoption was noted as a leading barrier to EHR adoption and was also identified among the leading barriers in our study.

Current EDR use is higher among younger dentists in the United States, likely due to adoption of EDRs by U.S. dental schools for training dental students. ${ }^{24}$ Adopting an unfamiliar paper-based environment in their private practices is highly unlikely for this subset of dentists. Notably, demographic evaluation of the $33 \%$ of dental practices with no EDR that indicated no plans for adoption determined they were largely older, male, engaged in solo practices, and in practice for $>26$ years (Figure 2).

Ramoni et $\mathrm{al}^{25}$ surveyed 814 dental team practitioners of a large private dental practice with offices in three states across the Pacific Northwest regarding their attitudes/beliefs related to establishment and use of standardized diagnostic terminology. ${ }^{25}$ With a robust response rate of $92 \%$, their study reported an overarchingly positive attitude towards clinical implementation of diagnostic terminology for improving intradisciplinary communication and communication between practitioners and patients. Increasingly, a growing interest in platforms reinforcing interdisciplinary interoperability to support integrated medical-dental care delivery models is an emergent factor that may further drive health record adoption in the future. ${ }^{26}$ These reports reflect further positive directions associated with increased implementation of clinical computing as reported in the current study.

Cost/expense of the EDRs, cost-benefit ratio, time to convert from paper-based to computer-based practice, and poor usability of the current EDRs remained as the top barriers cited for adoption of EDRs. Notably, within the time frame that approximately parallels that of our survey study, Walji et $\mathrm{al}^{27}$ identified usability issues and, in collaboration with vendors, set up timelines to systematically solve identified problems. Such studies are strategic in achieving high functioning EDRs for use in the clinical setting and diminishing barriers to EDR adoption. Our results indicate there is still debate over the relative security of paper-based versus computer-based patient dental records, and the opinions of U.S. dental providers are divided equally around this issue. Despite mixed perception surrounding EDRs, 75\% of survey responders indicated they would recommend EDRs to dentists starting a new practice. Ease of access to patient information emerged as the top advantage of EDRs, while concerns regarding technology reliability as the top disadvantage.

Notably, only $15 \%$ of respondents had adopted the use of patient portals in their practice based on survey data. A patient health portal is a web-based resource that provides a secure, HIPAA-compliant, two-way communication channel between patients and their health care providers. ${ }^{28,29}$ A patient health portal offers potential benefits to patients and provider organizations by improving both quality and access to care through features that enable patients to communicate electronically and securely with providers. ${ }^{30,31}$ Generally, patients using patient health portals tend to report greater satisfaction with provider communications and overall care. ${ }^{32}$ This trend is important to follow in future studies.

\section{Conclusion}

Although the majority of dentists surveyed in the United States were unfamiliar with the HITECH EHR incentive program available to them, the rate of adoption of EDRs by U.S. dentists to support chairside practice out-distanced the adoption rate by medical practitioners to support clinical practice in 2012. It would be important to determine the direction of this trend in the future. Use of EDRs is higher among younger dentists in the United States. Top barriers for adoption of EDRs identified in this survey included cost/ expense of EDRs, cost-benefit ratio, time to convert from paper-based to computer-based practice, and poor usability of current EDRs. Adoption rates of patient portals among dental practices in the United States were low. Finally, the approach piloted for targeting a defined sample of returned responses through modeling return rates from multiple mailings was effective in achieving the targeted national sample. However, more studies will be needed to further validate this alternative approach for survey research.

\section{Acknowledgements}

The authors thank Crystal Gumz, Lauren Janes, Neel Shimpi, and Cathy Schneider of the Biomedical Informatics Research Center for their assistance with the mailings conducted for this study. The authors thank Cathy Schneider for helping with the manual validation of the data entry process to verify accuracy of the data. Finally, the authors also thank Dr. Ingrid Glurich, Institute for Oral and Systemic Health project scientist and Marie Fleisner from the Office of Scientific Writing at Marshfield Clinic Research Foundation for assistance with reviewing and editing this manuscript.

\section{References}

1. Schleyer TK, Thyvalikakath TP, Spallek H, Torres-Urquidy MH, Hernandes P, Yuhaniak J. Clinical computing in general dentistry. J Am Med Inform Assoc. 2006;13:344-352.

2. Irwin JY, Tores-Uquidy MH, Schleyer T, Monaco V. A preliminary model of work during initial examination and treatment planning appointments. Br Dent J. 2009;206:E1.

3. American Dental Association Survey Center. In: 2006 Technology Survey. Chicago: American Dental Association; 2007. 22-37.

4. Dental Health Information Technology Survey. Edge Research. April 2010.

5. Schleyer T, Song M, Gilbert GH, Rindal DB, Fellows VV, Gordan VV, Funkhouser E.Electronic dental record use and clinical information management patterns among practitionerinvestigators in The Dental Practice-Based Research Network. J Am Dent Assoc. 2013;144:49-58.

6. Blumenthal D. Launching HITECH. N Engl J Med. 2010;362:382-385.

7. Blumenthal D. Implementation of the federal health information technology initiative. N Engl J Med. 2011;365:2426-2431. 
8. American Dental Association News, June 21, 2010, Electronic Health Record: Will federal government require it by 2014 ? Available at: http://www.ada.org/news/4306.aspx. Accessed February 4, 2017.

9 Edlestein BL. Federal supports for state oral health plans. J Publ Health Dent. 2012;72:S54-S59.

10. Chyou PH, Schroeder D, Schwei K, Acharya A. Statistical application and cost saving in a dental survey. Clin Med Res. 2017; 15:1-5.

11. Elo S, Kyngäs H. The qualitative content analysis process. J Adv Nurs. 2008;62:107-115.

12. Forman J, Damschroder L. Qualitative content analysis. In: Jacoby L, Siminoff LA, eds. Empirical Research for Bioethics: A Primer. Oxford, UK: Elsevier Publishing; 2008. 39-62.

13. American Dental Association Survey Center. 2012 Distribution of Dentists survey. Chicago: American Dental Association; 2011.

14. American Dental Association. Health Policy Institute. Supply of dentists. 2015. Available at: http://www.ada.org/en/scienceresearch/health-policy-institute/data-center/supply-of-dentists. Accessed February 4, 2017.

15. Cook JV, Dickinson HO, Eccles MP. Response rates in postal surveys of healthcare professionals between 1996 and 2005: an observational study. BMC Health Services Res. 2009;9:160.

16. Anderson R, Schiedermayer D. The social history matters! Acad Med. 2010;85:1103.

17. DesRoches CM, Charles D, Furukawa MF, Joshi MS, Kralovec P, Mostashari F, Worzala C, Jha AK. Adoption Of electronic health records grows rapidly, but fewer than half of US hospitals had at least a basic system in 2012. Health Affairs (Millwood). 2013;32:1478-1485.

18. Kalenderian E, Walji M, Ramoni RB. "Meaningful use" of EHR in dental school clinics: how to benefit from the U.S. HITECH Act's Financial and quality improvement incentives. J Dent Educ. 2013;77:401-415.

19. Powell VJ, Acharya A, Mahnke A, Din FM, Thyvalikakath TP. Metrics and Measurements.In: Powell VJ, Din FM, Achary A, Torres-Uquidy MH, eds. Integration of Medical and Dental Care and Patient Data. London: Springer, Health Informatics Series; 2012.Vol 3:139-165. Isbn: 978-1-4471-2185-5. doi: 10.1007/978-1-4471-2185-5_3;

20. Hsiao C-J, Hing E, Ashman J. Trends in electronic health record system adoption among office-based physicians: United States, 2007-2012. National Health Statistics Report \# 75, May 20, 2014. Available at: http://www.cdc.gov/nchs/ data/nhsr/nhsr075.pdf. Accessed April 20, 2016.

21. Health IT Dashboard. Electronic Health Record Adoption. EHR Adoption by Office-Based Providers. 2012. Available at: http://dashboard.healthit.gov/HHSONCHIEVIEWSLAB/. Accessed February 4, 2017.

22. Kruse CS, Kothman K, Anerobi K, Abanaka L. Adoption Factors of the Electronic Health Record: a systematic review. JIMR Med Inform 2016;4(2):e19.

23. Hamid F, Cline TW. Providers' acceptance factors and their perceived barriers to electronic health record (EHR) adoption. Online Journal of Nursing Informatics 2013;17. Available at: http://ojni.org/issues/?p=2837. Accessed November 7, 2017.

24. White JM, Kalenderian E, Stark PC, Ramoni RL, Vaderhobli R, Walji MF. Evaluating a dental diagnostic terminology in an electronic health record. J Dent Educ. 2011;75:605-615.

25. Ramoni RB, Walji MF, Kim S, McClellan L, Simmons K, Skourtes E, Yansane A, White JM, Kalenderian E. Attitudes toward and beliefs about the use of a dental diagnostic terminology: a survey of dental care providers in a dental practice. J Am Dent Assoc 2015;146:390-397.
26. Kalenderian E, Halamka JD, Spallek H. An EHR with teeth. Appl Clin Inform 2016;7:425-429.

27. Walji MF, Kalenderian E, Tran D, Kookal KK, Nguyen V, Tokede O, White JM, Vaderhobli R, Ramoni R, Stark PC, Kimmes NS, Schoonheim-Klein ME, Patel VL. Detection and characterization of usability problems in structured data entry interfaces in dentistry. Int J Med Inform 2013;82:128-138.

28. Horowitz AM, Robinson LA, Ng MW, Acharya A. After Visit Summaries: A Tool Whose Time Has Come for Use in Dentistry. Institute of Medicine of the National Academies: 2014. Avaialble at: http://www.iom.edu/ /media/Files/ Perspectives-Files/2014/Discussion-Papers/ aftervisitsummaries.pdf. Accessed February 4, 2017.

29. Tang PC, Ash JS, Bates DW, Overhage JM, Sands DZ. Personal health records: definitions, benefits, and strategies for overcoming barriers to adoption. J Am Med Inform Assoc. 2006;13:121-126.

30. Emont S. Measuring the Impact of Patient Portals: What the Literature Tells Us. Oakland, CA: California HealthCare Foundation; 2011 Avaialble at: http://www.chcf.org/ /media/ MEDIA\%20LIBRARY\%20Files/PDF/M/PDF\%20 MeasuringImpactPatientPortals.pdf. Accessed Feburary 4, 2017.

31. Lin CT, Wittevrongel L, Moore L, Beaty BL, Ross SE. An Internet-based patient-provider communication system: randomized controlled trial. J Med Internet Res. 2005;7:e47.

32. Zickmund SL, Hess R, Bryce CL, Mc Tigue K, Olshansky E, Fitzerald K, Fisher GS. Interest in the use of computerized patient portals: role of the provider-patient relationship. J Gen Intern Med. 2008;23:20-26.

\section{Author Affiliations}

Amit Acharya, BDS, PhD*; Dixie Schroeder, MBA*; Kelsey Schwei, PhD*; and Po-Huang Chyou, PhD†

*Center for Oral and Systemic Health, Marshfield Clinic Research Institute, Marshfield, Wisconsin, USA $\uparrow$ Biomedical Informatics Research Center, Marshfield Clinic Research Institute, Marshfield, Wisconsin, USA 
Appendix 1. Marshfield Clinic Research Institute's Electronic Dental Record Adoption Survey Tool.

\section{Demographics}
1. Age:
$20-29$
$30-39$
$40-49$
$50-59$
$60-69$
Over 70

2. Gender: $\bigcirc$ Female $\bigcirc$ Male

3. Ethnicity:
White
Black/African A.
Asian
A. Indian/Alaska Nat.
Hawaiian N. \& Pacific Is.
Mixed Race Background
Other

4. What dental college did you graduate from:

5. Number of years in practice:

\section{Practice Demographics}

6. Is your practice: $\bigcirc$ solo $\bigcirc$ Group

If group, number of dentists:

7. What is your specialty? (Check all that apply)
$\square$ General Dentistry
$\square$ Endodontics
$\square$ Oral and Maxillofacial Pathology
$\square$ Orthodontics
$\square$ Oral and Maxillofacial Surgery
$\square$ Pedodontics
$\square$ Oral and Maxillofacial Radiology
Periodontics
$\square$ Public Health Dentistry
Prosthodontics

8. If you are in a group practice, what other specialties are in your practice? (Check all that apply)
$\square$ Not in group practice
$\square$ Endodontics
$\square$ General Dentistry
$\square$ Orthodontics
$\square$ Oral and Maxillofacial Pathology
Pedodontics
$\square$ Oral and Maxillofacial Surgery
$\square$ Periodontics
$\square$ Oral and Maxillofacial Radiology
$\square$ Public Health Dentistry
None

9. In what state is your practice located:

10. What type of area is your practice in (Check all that apply) :
$\square$ Rural/Small town
$\square$ Suburban
$\square$ Urban
$\square$ Other:

11. How many operatories are in your practice:

\section{Technology at Practice}

12. How would you rate your experience with computers?

$\begin{array}{cccc}\text { Very } & \text { Somewhat } & \text { Somewhat } & \text { Very } \\ \text { comfortable } & \text { comfortable } & \text { Neutral } & \text { uncomfortable uncomfortable }\end{array}$

13. Where are computers used in your practice? (Check all that apply)

$\square$ Waiting room $\quad \square$ Chair-side in operatories
$\square$ Front desk $\square$ Other:
$\square$ Provider or staff offices

14. How many operatories have access to a computer:

15. How many chair-side computers are connected to the internet in your practice:

16. What devices/technologies do you use in your practice? (Check all that apply)

$\square$ iPad/Tablets

$\square$ Smart Phone/PDA

$\square$ Digital Radiographs

(Which software program:

CAD-CAM (Which system:

Other:

17. What type of information do you seek on the internet to aid in your practice? (Check all that apply)

$\square$ Vendor/products $\square$ Evidenced-based information

$\square$ Referrals

$\square$ IT support

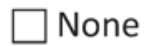

$\square$ Educational material

18. How essential is the Internet for your practice?

\begin{tabular}{|c|c|c|c|}
\hline $\begin{array}{c}\text { Very } \\
\text { essential } \\
\bigcirc\end{array}$ & $\begin{array}{c}\text { Somewhat } \\
\text { essential } \\
\bigcirc\end{array}$ & $\begin{array}{c}\text { Neutral } \\
\bigcirc\end{array}$ & $\begin{array}{c}\text { Not very } \\
\text { essential } \\
\bigcirc\end{array}$ \\
\hline
\end{tabular}

19. In what format(s) does your practice offer patient education? (Check all that apply)

$\square$ Electronically (computer, $\square$ Internet video, CD, flash drive) $\quad \square$ Patient portal

$\square$ Paper (walk-out $\square$ None Statement, brochure) $\square$ Other:

$\square$ Face-to-face

20. What resource(s) do you utilize for patient education? (Check all that apply)

$\square$ Software application: Casey, Consult-pro, Guru, Side Kick MP, Orasphere, Media Med

$\square$ Own clinical materials

$\square$ None

$\square$ Other: 
21. Does your practice offer a patient portal for your patients to view their dental information?

$\bigcirc$ Yes* $\bigcirc$ No

*If Yes, what feature(s) does it offer? (Check all that apply)

$\square$ Scheduling, rescheduling, or viewing a past/future appointment

$\square$ Updating insurance information

$\square$ Health reminders

$\square$ Educational health information

$\square$ Refilling a prescription

$\square$ Paying a dental bill

$\square$ Reviewing a test result

$\square$ Seeing my health summary

Accessing patient forms and online services

Other:

22. Does your practice use Social Media?

Yes * $\bigcirc$ No

*If Yes, which ones? (Check all that apply)
$\square$ Facebook
$\square$ You Tube
$\square$ LinkedIn
$\square$ Other:

Twitter

*If Yes, for what purposes does your practice use Social

Media? (Check all that apply)

$\begin{array}{ll}\square \text { Networking } & \square \text { Communication } \\ \square \text { Marketing } & \square \text { Other: }\end{array}$

\section{EDR Adoption Rate}

23. How important do you feel it is for your practice to have an Electronic Dental Record (EDR)?

\begin{tabular}{|c|c|c|c|c|}
\hline $\begin{array}{c}\text { Very } \\
\text { mportant }\end{array}$ & Important & $\begin{array}{l}\text { Moderately } \\
\text { important }\end{array}$ & $\begin{array}{c}\text { Of little } \\
\text { importance }\end{array}$ & Unimportar \\
\hline
\end{tabular}

24. Rate your comfort level with the EDR:

\begin{tabular}{ccccc}
$\begin{array}{c}\text { Very } \\
\text { comfortable }\end{array}$ & $\begin{array}{c}\text { Somewhat } \\
\text { comfortable }\end{array}$ & $\begin{array}{c}\text { Somewhat } \\
\text { uncomfortable }\end{array}$ & $\begin{array}{c}\text { Very } \\
\text { uncomfortable }\end{array}$ \\
\hdashline & $\bigcirc$ & $\bigcirc$ & $\bigcirc$
\end{tabular}

25. What do you believe are the advantages of using an EDR?

26. What do you believe are the disadvantages of using an EDR?

72 Electronic dental record and clinical computing adoption
27. Do you currently use an Electronic Dental Record (EDR)?

$\bigcirc$ Yes* $\bigcirc$ Not

*If Yes, when did your practice go live with the EDR?

Within the last 12 months

$1-2$ years ago

$3-5$ years ago

More than 6 years ago

*Which practice management system (PMS) do you use?
Axium
SoftDent
Curvedental
Dentrix Enterprise
EasyDent
$\bigcirc$ EagleSoft
PracticeWorks
Open Dental
OQSI Dental
Don't know

Other:

*What mechanism(s) do you use to input information

into the EDR? (Check all that apply)
$\square$ Touch Screen
$\square$ Voice Recognition
Mouse/Keyboard
Other:

†If No, what is the main reason?

tDo you plan to purchase an EDR in the future?
O $0-6$ months
More than 2 years
7-11 months
No
$1-2$ years
Not sure

28. Rate these statements relating to EDR:

28a. Paper dental records are more secure than electronic dental records.

Strongly

agree

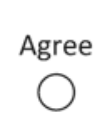
Undecided
$\bigcirc$

Disagree

Strongly

0

28b. Electronic dental records improve efficiency for a dentist and/or dental staff.

Strongly

agree

0

Agree

Undecided

$\bigcirc$

Strongly disagree

28c. Electronic dental records cost more than they are worth.

Strongly

agree

$\bigcirc$

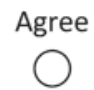

Undecided

$\bigcirc$

Disagree

Strongly

$28 \mathrm{~d}$. Electronic dental records require more time to complete than comparable paper record documentation.

Strongly

agree

0

Agree

Undecided

Disagree

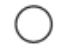

Strongly disagree

28e. Electronic dental records improve patient care. Strongly agree

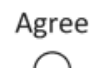

Undecided

Disagree

Strongly
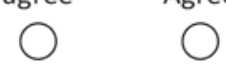
28f. I would recommend the use of electronic dental records to dentists starting a new practice.

Strongly

agree

Agree

Undecided

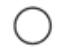

Disagree

$\bigcirc$

disagree

$28 \mathrm{~g}$. Electronic dental records improves legibility.

Strongly agree

Agree

Undecided

$\bigcirc$

Disagree

Strongly

0

O

$\bigcirc$

disagree

Meaningful Use/American Recovery and Reinvestment Act (ARRA):

29. How familiar are you with the ARRA incentives available for the implementation of EDRs?

$\begin{array}{ccccc}\begin{array}{c}\text { Very } \\ \text { familiar* }\end{array} & \begin{array}{c}\text { Somewhat } \\ \text { familiar* }\end{array} & \text { Unsure } & \begin{array}{c}\text { Somewhat } \\ \text { unfamiliar }\end{array} & \begin{array}{c}\text { Very } \\ \text { unfamiliar }\end{array} \\ & \bigcirc & \bigcirc & \bigcirc & \end{array}$

*If familiar, how did you hear about the ARRA

meaningful use incentive program? (Check all that apply)
$\square$ Vendor
$\square$ Colleague
$\square$ Internet source
$\square$ Other:

Journal or other print source

30. Are you interested in learning more regarding the ARRA meaningful use incentive program?

$\begin{array}{ccccc}\text { Very } & \text { Somewhat } & & \text { Not very } & \text { Not at all } \\ \text { interested } & \text { interested } & \text { Neutral } & \text { interested } & \text { interested } \\ \bigcirc & \bigcirc & \bigcirc & \bigcirc & \bigcirc\end{array}$

31. Are you planning to apply for the ARRA meaningful use incentive program?

$\bigcirc$ Yes, it has already been implemented or in the process of being implemented

Yes, within the next year

Yes, but unsure when

No, the program isn't of interest to me

Unsure

32. This question should be answered by those who are already part of the ARRA meaningful use program.

What barriers or challenges, if any, have you encountered in implementation of the Meaningful Use of a certified EDR? (Check all that apply)

$\square$ Having interest but not meeting minimum qualification for patient percentages

$\square$ Finding a certified system suited to the workflow of the office

$\square$ Difficulty meeting any of the defined core and menu objectives or clinical quality measurements

I have not faced any barriers or challenges Other
Nationwide Health Information Network (NHIN)/ Health Information Exchange (HIE)

33. How familiar are you with the Nationwide Health Information Network (NHIN)?

$\begin{array}{ccccc}\begin{array}{c}\text { Very } \\ \text { familiar* }\end{array} & \begin{array}{c}\text { Somewhat } \\ \text { familiar* }\end{array} & \text { Unsure } & \begin{array}{c}\text { Somewhat } \\ \text { unfamiliar }\end{array} & \begin{array}{c}\text { Very } \\ \text { unfamiliar }\end{array} \\ \bigcirc & \bigcirc & \bigcirc & \bigcirc & \bigcirc\end{array}$

34. How familiar are you with NHIN associated interfaces The Direct Project and CONNECT?

$\begin{array}{ccccc}\begin{array}{c}\text { Very } \\ \text { familiar* }\end{array} & \begin{array}{c}\text { Somewhat } \\ \text { familiar* }\end{array} & \text { Unsure } & \begin{array}{c}\text { Somewhat } \\ \text { unfamiliar }\end{array} & \begin{array}{c}\text { Very } \\ \text { unfamiliar }\end{array} \\ \bigcirc & \bigcirc & \bigcirc & \bigcirc & \bigcirc\end{array}$

*If familiar, how did you hear about the NHIN? (Check all that apply)

$\square$ Internet source

$\square$ Journal or other print source

$\square$ Colleague

$\square$ Other:

35. Are you interested in learning more regarding the NHIN?

$\begin{array}{ccccc}\begin{array}{c}\text { Very } \\ \text { interested }\end{array} & \begin{array}{c}\text { Somewhat } \\ \text { interested }\end{array} & \text { Neutral } & \begin{array}{c}\text { Not very } \\ \text { interested }\end{array} & \begin{array}{c}\text { Not at all } \\ \text { interested }\end{array} \\ \bigcirc & \bigcirc & \bigcirc & \bigcirc & \bigcirc\end{array}$

36. Are you interested in participating in the NHIN or other HIE?

$\begin{array}{ccccc}\begin{array}{c}\text { Very } \\ \text { interested }\end{array} & \begin{array}{c}\text { Somewhat } \\ \text { interested }\end{array} & \text { Neutral } & \begin{array}{c}\text { Not very } \\ \text { interested }\end{array} & \begin{array}{c}\text { Not at all } \\ \text { interested }\end{array} \\ \bigcirc & \bigcirc & \bigcirc & \bigcirc & \end{array}$

37. Do you already participate in a network or exchange?

$\bigcirc$ Yes $\bigcirc$ No

Why or why not?

38. Do you currently participate in a privately sponsored Health Information Exchange (HIE) program with other dental or medical offices?

$\bigcirc$ Yes* $\bigcirc$ No

*If Yes, how many practices participate in the network?
1- 5
11- 20
6-10
More than 20

*If Yes, what types of groups/offices are involved? 
Method of Storage \& Data Entry Responsibility/ Modalities (EDR):

39. Storage of major clinical information categories on paper/computer (Check all that apply)

\begin{tabular}{|c|c|c|c|c|c|c|c|}
\hline \multirow[b]{2}{*}{ Information Type } & \multicolumn{3}{|c|}{ Storage method } & \multicolumn{4}{|c|}{ Data Entry By } \\
\hline & Paper & Computer & None & Dentist & Hygienist & Assistant & $\begin{array}{l}\text { Front } \\
\text { Desk }\end{array}$ \\
\hline Patient accounting \& billing & $\square$ & $\square$ & $\square$ & $\square$ & $\square$ & $\square$ & $\square$ \\
\hline Insurance details & $\square$ & $\square$ & $\square$ & $\square$ & $\square$ & $\square$ & $\square$ \\
\hline Expense reports & $\square$ & $\square$ & $\square$ & $\square$ & $\square$ & $\square$ & $\square$ \\
\hline Patient appointments & $\square$ & $\square$ & $\square$ & $\square$ & $\square$ & $\square$ & $\square$ \\
\hline Chief complaint & $\square$ & $\square$ & $\square$ & $\square$ & $\square$ & $\square$ & $\square$ \\
\hline Oral health status & $\square$ & $\square$ & $\square$ & $\square$ & $\square$ & $\square$ & $\square$ \\
\hline Alerts & $\square$ & $\square$ & $\square$ & $\square$ & $\square$ & $\square$ & $\square$ \\
\hline Prescriptions & $\square$ & $\square$ & $\square$ & $\square$ & $\square$ & $\square$ & $\square$ \\
\hline Medication history & $\square$ & $\square$ & $\square$ & $\square$ & $\square$ & $\square$ & $\square$ \\
\hline Dental history & $\square$ & $\square$ & $\square$ & $\square$ & $\square$ & $\square$ & $\square$ \\
\hline Medical history & $\square$ & $\square$ & $\square$ & $\square$ & $\square$ & $\square$ & $\square$ \\
\hline Social History & $\square$ & $\square$ & $\square$ & $\square$ & $\square$ & $\square$ & $\square$ \\
\hline Family dental history & $\square$ & $\square$ & $\square$ & $\square$ & $\square$ & $\square$ & $\square$ \\
\hline Family medical history & $\square$ & $\square$ & $\square$ & $\square$ & $\square$ & $\square$ & $\square$ \\
\hline Intra-oral examination & $\square$ & $\square$ & $\square$ & $\square$ & $\square$ & $\square$ & $\square$ \\
\hline Extra-oral examination & $\square$ & $\square$ & $\square$ & $\square$ & $\square$ & $\square$ & $\square$ \\
\hline Periodontal charting & $\square$ & $\square$ & $\square$ & $\square$ & $\square$ & $\square$ & $\square$ \\
\hline Tooth charting & $\square$ & $\square$ & $\square$ & $\square$ & $\square$ & $\square$ & $\square$ \\
\hline Test results & $\square$ & $\square$ & $\square$ & $\square$ & $\square$ & $\square$ & $\square$ \\
\hline Intra-oral images & $\square$ & $\square$ & $\square$ & $\square$ & $\square$ & $\square$ & $\square$ \\
\hline Extra-oral images & $\square$ & $\square$ & $\square$ & $\square$ & $\square$ & $\square$ & $\square$ \\
\hline Radiographic images & $\square$ & $\square$ & $\square$ & $\square$ & $\square$ & $\square$ & $\square$ \\
\hline $\begin{array}{l}\text { Consults/reports to/from other dentists or health } \\
\text { providers }\end{array}$ & $\square$ & $\square$ & $\square$ & $\square$ & $\square$ & $\square$ & $\square$ \\
\hline Risk assessment & $\square$ & $\square$ & $\square$ & $\square$ & $\square$ & $\square$ & $\square$ \\
\hline Problem list & $\square$ & $\square$ & $\square$ & $\square$ & $\square$ & $\square$ & $\square$ \\
\hline Treatment plans & $\square$ & $\square$ & $\square$ & $\square$ & $\square$ & $\square$ & $\square$ \\
\hline Diagnoses & $\square$ & $\square$ & $\square$ & $\square$ & $\square$ & $\square$ & $\square$ \\
\hline Prognosis & $\square$ & $\square$ & $\square$ & $\square$ & $\square$ & $\square$ & $\square$ \\
\hline Progress notes & $\square$ & $\square$ & $\square$ & $\square$ & $\square$ & $\square$ & $\square$ \\
\hline Completed treatment & $\square$ & $\square$ & $\square$ & $\square$ & $\square$ & $\square$ & $\square$ \\
\hline Patient education/instructions & $\square$ & $\square$ & $\square$ & $\square$ & $\square$ & $\square$ & $\square$ \\
\hline
\end{tabular}

If you would like to be included in a drawing for one of two iPads, please provide your contact information:

Name and phone number or

Email address 